Л.Н.Полубояринова

\title{
Европейские связи Ф.М.Достоевского: подходы российской компаративистики
}

Творчество Ф.М.Достоевского начинает осваиваться российской национальной школой компаративистики достаточно поздно, и эта ситуация по-своему парадоксальна. Казалось бы, именно Достоевский - «гениальный читатель», «гениальный истолкователь чужого творчества», вся проблематика произведений которого «уже заложена была в творчестве предшественников его» ${ }^{1}$, автор, переводивший на русский язык Бальзака, бредивший в юные годы Шиллером и зачитывавшийся Диккенсом и Вальтером Скоттом, как никакой другой писатель годится для изучения с точки зрения сравнительного литературоведения. Однако интерес этот просыпается со значительным опозданием.

Основоположник российской компаративистики младший современник Достоевского профессор Санкт-Петербургского университета Александр Николаевич Веселовский (1838-1906) изучал мировые связи славянского фольклора, европейские связи Василия Жуковского ${ }^{2}$ и множество других материй сравнительного толка. Достоевский, однако, в сферу его научных интересов не вошел. Факт не-обращения Веселовского к Достоевскому понятен: масштабность творчества автора и интернациональный диапазон его рецепции в пору деятельности Веселовского пока еще осознаны не были.

Причины скорее идеологического порядка препятствовали заниматься Достоевским продолжателю компаративистской традиции в ПетербургскомЛенинградском университете Виктору Максимовичу Жирмунскому (1891-1971). В его этапной монографии «Гете в русской литературе» (1937) очевидные связи, например, романа «Братья Карамазовы» с «Фаустом» Гете даже не рассматриваются как таковые, о них лишь вскользь упоминается в контексте критики статьи религиозного философа Сергея Булгакова «Иван Карамазов как философский тип» $(1901)^{3}$. И это - несмотря на высказанное еще в конце XIX века и наверняка известное Жирмунскому высказывание чешского компаративиста Томаша Масарика: «Сравнительное изучение «Фауста» Гете и «Братьев Карамазовых» Достоевского скажет о немецком и русском характере больше, чем дюжины славянских и немецких патриотических излияний» ${ }^{4}$.

\footnotetext{
${ }^{1}$ Бем А. Достоевский - гениальный читатель // Бем А. О Достоевском. - М.: Русский путь, 2007. - С.206.

${ }^{2}$ См.: Веселовский А.Н. В.А.Жуковский. Поэзия чувства и «сердечного воображения». - СПб.: Типография Имп. Академии наук, 1904.

3 Жирмунский В.М. Гете в русской литературе. 2-е изд. - Л.: Наука, 1981. - С.446.

${ }^{4}$ Цит. по: Бем А.Л. Исследования. Письма о литературе. - М.: Языки славянской культуры, 2001. - С.158.
} 
Достоевский как религиозный пророк, как самоидентификационная фигура русской национальной культуры и как сублимированное воплощение eе издержек, «неприглядных», «нигилистических» качеств, - эти два полюса отношения к Достоевскому русского национального культурного дискурса достаточно отчетливо обозначились лишь после смерти писателя в 1881 г. - религиозным философом Владимиром Соловьевым, (в его речи 1881 г. «В память Достоевского») с одной стороны, и - представителем народнической критики Н.М.Михайловским (статья «О Достоевском и г. Мережковском» 1902 г.) - с другой.

Данные две крайности сменяли друг друга на протяжении XX века, и ритм их смены чаще всего не совпадал с чередованием приливов и отливов интереса к русскому классику в интернациональном масштабе. Так, в культуре Западной Европы, США и Японии русский автор был осознан лишь в первой трети XX века. Именно в это время в Советском Союзе складывается неблагоприятная ситуация для изучения творчества Достоевского, объявленного «реакционным» автором-почвенником. В советских программах изучения литературы в школе и школьных учебниках творчество Достоевского до конца 1960-х гг. представлено исключительно на уровне краткого очерка в обзорной главе, с расстановкой «классовых» акцентов ${ }^{5}$. Маргинализация Достоевского была особенно очевидна на фоне другого русского классика - Льва Толстого, «легитимированного» для изучения в советское время благодаря высказываниям о нем Ленина, в частности, благодаря статье последнего «Лев Толстой как зеркало русской революции» (1908). По аналогии с употребленным Горьким словом «карамазовщина» (в статьях «О карамазовщине», «Еще о карамазовщине», обе 1913 г.) активно задействуется выражение «достоевщина». Оно вошло в словарь русского языка под редакцией Д.Н.Ушакова за 1935-1940 г. с откровенно негативной коннотацией, как «1. Психологический анализ в манере Достоевского (с оттенком осуждения). 2. Душевная неуравновешенность, острые и противоречивые душевные переживания, свойственные героям романов Достоевского» ${ }^{6}$.

Ситуация меняется в 1970-е гг., когда в Советском Союзе снимается, наконец, идеологический запрет на Достоевского, он вводится в школьные программы по литературе, издается (с 1972 г.) его 30-томное собрание сочинений ${ }^{7}$. Именно семидесятые

\footnotetext{
${ }^{5}$ Ср., например, фразы из учебника 1956 г. : «В произведениях Достоевского 70-80-х годов еще резче проявилось непонимание автором передовых идей современного ему общества.», «В. И. Ленин беспощадно осуждал ложные тенденции творчества Достоевского...» (Пономарев Е. Чему учит учебник // Нева. - 2010. № 6. С.196).

${ }^{6}$ Большой толковый словарь современного русского языка: В 4 т. / Под ред. Д. Н. Ушакова. - Т.1. М., 19351940. URL: http://ushakovdictionary.ru/word.php?wordid=14043 (дата обращения: 02.02.2014)

${ }^{7}$ Достоевский Ф.М. Полное собрание сочинений в 30 тт. - Л.: Наука, 1972-1990.
} 
годы прошлого века становятся для советской компаративистики временем активного изучения европейских и мировых связей Достоевского. Это касается как европейских его претекстов, так и проблемы рецепции Достоевского в мировой литературе.

Впрочем, начало этому направлению «достоевсковедения» было положено еще в 1920-е гг., в работах Л.П.Гроссмана ${ }^{8}$, Г.Н.Поспелова ${ }^{9}$, Б.Г.Реизова ${ }^{10}$, Д.И.Чижевского ${ }^{11}$, и М.М.Бахтина ${ }^{12}$, в которых были рассмотрены, соответственно, французские (О. де Бальзак, Э.Сю, В.Гюго), английские (Ч.Диккенс), немецкие (Ф.Шиллер) и античные (жанры платоновского диалога, мениппеи, солилоквиума) источники романов Достоевского. Пальма первенства в самой постановке вопроса о Достоевском как авторе мирового значения, в лице которого «эволюция европейского романа пережила один из своих самых крупных революционных этапов, в корне преобразивших ее вековые традиции, навыки и предания», ${ }^{13}$ принадлежит, без сомнения, Л.П.Гроссману. Исследования Д.И.Чижевского, посвященные связи Достоевского с немецкой литературной и философской традицией, в частности, с творчеством Ф.Шиллера, вынужденно публиковавшиеся на немецком языке, лишь в последнее время становятся достоянием отечественной линии изучения Достоевского ${ }^{14}$.

Б.Г.Реизов, начинавший свой путь в науке с публикации статьи об английских связях Достоевского, впоследствии состоялся как компаративист широкого диапазона, исследовавший литературные контакты русской, французской, английской, итальянской, португальской и бразильской литератур. Главной темой Реизова была рецепция Вальтера Скотта в русской прозе XIX века. Однако и раннему своему предмету - изучению европейского контекста творчества Достоевского - этот ученый и впоследствии уделяет достаточно внимания. В частности, в 1960-е-1970-е гг. он выпускает несколько важных работ о европейских связях Достоевского ${ }^{15}$, в которых обращает внимание на французские

\footnotetext{
${ }^{8}$ Гроссман Л.П. Поэтика Достоевского. - М.: Гос. академия худож. наук, 1925.

${ }^{9}$ Поспелов Г.Н. “Eugenie Grandet” в переводе Ф.М.Достоевского // Учен. Зап. Ин-та яз. и лит. РАНИОН. 1928. - Т.2. С.103-136.

${ }^{10}$ Реизов Б.Г. О западном влиянии в творчестве Ф.М.Достоевского. Некоторые западные источники романа «Униженные и оскорбленные» // Известия Северо-Кавказского университета. - 1927. - Т.1. - С.95-104.

${ }^{11}$ Tschizevskij D. Schiller und die „Brüder Karamazov“// Zeitschrift für slavische Philologie. - 1929. - Bd. 6. - H. 1-2. - S. 1-42.

12 Бахтин М.М. Проблемы творчества Достоевского. - Л.: Прибой, 1929.

${ }^{13}$ Гроссман Л.П. Поэтика Достоевского. URL:

http://az.lib.ru/g/grossman_1_p/text_1925_poetika_dostoevskogo.shtml (дата обращения 02.02.2014)

${ }^{14}$ См., в частности, русский перевод упомянутой статьи Д.Чижевского о Шиллере и Достоевском:

Чижевский Д.М. Шиллер и «Братья Карамазовы» // Достоевский: материалы и исследования. Т. 19. - СПб.: Наука, 2010. - С.16-57.

15 Реизов Б.Г. Диккенс и Достоевский («Село Степанчиково и его обитатели») // Реизов Б.Г. Труды по сравнительному литературоведению. - СПб.: изд-во Санкт-Петерб. ун-та, 2011.- С.517-528; Реизов Б.Г. «Преступление и наказание» и проблема европейской действительности // Там же. - С. 551-570; Реизов Б.Г.«Униженные и оскорбленные» Достоевского и проблемы зарубежной литературы // Там же. - 570-592; Реизов Б.Г. Борьба литературных традиций в «Братьях Карамазовых» // Там же. - C.529-550.
} 
(Жорж Санд, Бальзак, Золя), английские (Диккенс), немецкие (Гете, Шиллер) источники произведений русского автора.

Акцент на западных претекстах творчества Достоевского был в означенный период скорее исключением, чем правилом, в силу того, что в послевоенном контексте «русская литература стала рассматриваться как первая литература мира, ведущая за собой не только национальные литературы СССР, но и литературы народов Европы». Соответственно, «принципиально важной стала известность русских классиков за рубежом» ${ }^{16}$. Как следствие изучение интернациональных претекстов творчества Достоевского в последующие годы отчетливо оттесняется на второе место по сравнению с исследованием влияния русского автора на мировую литературу: имена Франца Кафки, Томаса Манна, Роберта Музиля, Альбера Камю как увлеченных и благодарных читателей русского классика говорят в данном случае сами за себя. Именно на исследовании рецепции Достоевского в западных литературах строится, в основном, монография Г.М. Фридлендера (1915-1995) «Достоевский и мировая литература» ${ }^{17}$. Данная тенденция, особенно очевидная на фоне «противонаправленной» установки, например, английских и американских исследователей, традиционно делающих акцент скорее на поиске западных источников Достоевского, ${ }^{18}$ отчасти сохраняется и в XXI веке ${ }^{19}$.

Ей противостоит явно наметившийся на форумах и в изданиях последних лет разворот к изучению западных источников Достоевского ${ }^{20}$ - теперь уже в свете современных теоретико-культурных парадигм. В частности, обращает на себя внимание интенсивная разработка диккенсовских претекстов в книге Н.Г.Михновец ${ }^{21}$. Исследование С.А.Кибальника актуализирует одну из наиболее ранних компаративистских тем

\footnotetext{
${ }^{16}$ Пономарев Е. Чему учит учебник. - С.177.

${ }^{17}$ Фридлендер Г.М. Достоевский и мировая литература. - Л.: Советский писатель, 1979. «Обратный» вектор влияния присутствует у Г.М.Фридлендера единственно в главе, посвященной Достоевскому и В.Гюго: с. 176-198.

18 Ср., например, исследования: Passage Ch.E. Dostoevsky the Adaptor. A Study in Dostoevsky's Use of The Tales of Hoffmann (Study in Comparative Literature). - Chapel Hill: University of North Carolina Press, 1954; Lary N.M. Dostoevsky and Dickens: A Study of Literary Influence. - London [u.a.]: Routledge \& Kegan Paul, 1973; Gronicke A. The Russian Image of Goethe. - Philadelphia: Univ. of Pennsylvania, 1985.

${ }^{19}$ Например, второй том «этапного» для последних двух десятилетий «достоевсковедения» двухтомника «Достоевский и ХХ век» (М.: ИМЛИ РАН, 2007), посвященный мировым связям русского классика, состоит преимущественно из материалов, иллюстрирующих влияние Достоевского на мировую литературу и не содержит практически ни одной статьи, в которой бы исследовались западные претексты писателя.

20 См. обзорную статью 2010 г.: Криницын А.Б. Творчество Достоевского в контексте европейской литературы. URL: http://www.portal-slovo.ru/philology/42345.php (дата обращения: 02.02.2014).

${ }^{21}$ Михновец Н.Г. Прецедентные произведения и прецедентные темы в диалогах культур и времен. Место и роль прецедентных явлений в творчестве Ф. М. Достоевского. - СПб.: Наука, САГА, 2006.
} 
отечественного достоевсковедения - «Достоевский и Бальзак» 22 , а в недавно вышедшей книге А.К.Степаняна ${ }^{23}$ подробно анализируется сервантесовский интертекст романов Достоевского.

В продолжение заявленной темы хотелось бы остановиться на одном интересном примере рецепции поэзии Фридриха Шиллера в творчестве Ф.М.Достоевского, до сих пор не получившем удовлетворительного истолкования.

В ряду западноевропейских источников Достоевского имя Фридриха Шиллера (Friedrich Schiller, 1759-1805) традиционно упоминается одним из первых. Русский писатель впервые соприкасается с творчеством Шиллера в десятилетнем возрасте на театральном представлении драмы «Разбойники», произведшей на него глубочайшее впечатление. Страстное увлечение шиллеровскими стихами и драмами, которые Достоевский читал как в оригинале, так и в русских переводах, ${ }^{24}$ дало свои плоды в пору собственного активного литературного творчества. Влияние Шиллера на протяжении всего творческого пути Достоевского - начиная от «Бедных людей» (1844) и заканчивая последними выпусками «Дневника писателя» (1880) и «Пушкинской речью» (1880), было неизменно интенсивным, хотя и приобретало на отдельных этапах творческой биографии разные формы ${ }^{25}$.

Фрагмент письма Ф.М.Достоевского к брату от 1 января 1840 г. и пассаж из «Дневника писателя» за июнь 1876 г. достаточно ярко иллюстрируют глубину, масштабность и - последовательность (между первым и вторым высказыванием - 36 лет!) воздействия Шиллера на русского классика. В восторженных излияниях восемнадцатилетнего юноши речь идет о глубоко личном переживании шиллеровских текстов: «Я вызубрил Шиллера, говорил им, бредил им; ... имя ... Шиллера стало мне родным, каким-то волшебным звуком, вызывающим столько мечтаний» ${ }^{26}$. Напротив, в зрелом суждении маститого писателя акцент переносится с индивидуального «я» на национально-культурную общность «мы»: «... у нас он [Шиллер], вместе с Жуковским, в душу русскую всосался, клеймо в ней оставил, почти период в истории нашего развития обозначил» ${ }^{27}$.

\footnotetext{
${ }^{22}$ Кибальник С. А. «Eugénie Grandet» О. де Бальзака в переводе Достоевского // Достоевский и мировая культура. - СПб.: Серебряный век, 2012. - С. 27-40.

${ }^{23}$ Степанян А.К. Достоевский и Сервантес: диалог в большом времени. - М.: Языки славянской культуры, 2013.

${ }^{24}$ В частности, брат Достоевского Михаил Михайлович (1820-1864), с которым писатель был очень близок, перевел на русский язык по побуждению писателя драмы Шиллера «Коварство и любовь» и «Дон Карлос» и эссе «О наивной и сентиментальной поэзии».

${ }^{25}$ О трех периодах рецепции Шиллера Достоевским см.: Lyngstad A. H. Dostoevskij and Schiller. - The Hague: Mouton, 1975. - P. 110.

${ }_{26}$ Достоевский Ф.М. Полное собрание сочинений и писем. В 30 т. Т. 28 (1). - Л.: Наука, 1985-1987. - С.69-71.

${ }^{27}$ Там же. Т. 20. - C.35.
} 
Общим, однако, остается принципиально важный момент усвоения и «присвоения» немецкого классика на индивидуальном или коллективном уровне, которое неизменно осмысляется в «телесной» метафорике. И в первом и во втором случаях речь идет о физической, почти механической интериоризации - инкорпорировании себе (в себя) шиллеровских текстов («вызубрить», «всосался», «клеймо ... оставил») с их последующим «экскорпорированием»- изверганием вовне в виде «говорения», «бреда», «мечтаний» или же факта национальной культурной истории («период в истории нашего развития обозначил»). При этом «волшебный звук» поэзии Шиллера, «возвращающийся» из «недр» тела или души присвоившего его индивида или же «отпечатавшийся» в виде клейма на «теле» национального коллектива, очевидно, перекодируется, наделяясь способностью репрезентировать теперь уже не самого (немецкого) автора - но реципиента - (русского) индивидуального или коллективного субъекта.

Данная функция поэзии Шиллера: выступать в ее рецептивном преломлении на русской почве в качестве медиума саморепрезентации читателя и, соответственно, маркировать индивидуальную и национальную культурную идентичность представляется, несмотря на обширность литературы, посвященной «русскому Шиллеру» в целом ${ }^{28}$ и проблеме «Шиллер и Достоевский» в отдельности ${ }^{29}$ - пока еще недостаточно изученной.

В частности, не получил удовлетворительной интерпретации факт «абсурдного» цитирования Дмитрием Карамазовым шиллеровских стихов в третьей главе третьей части первой книги романа «Братья Карамазовы», озаглавленной «Исповедь горячего сердца. В стихах». Заглавие это вполне соответствует содержанию. В самом деле, несколько перевозбужденный, в том числе и благодаря выпитой перед тем изрядной толике коньяку,

\footnotetext{
${ }^{28}$ См. из последних работ на эту тему: Фукс-Шиманская Л. Фридрих Шиллер и русский шиллеризм. Рецепция творчества Фридриха Шиллера в России 1800 - 1820 гг. - М.: Спутник+, 2009; Данилевский Р.Ю. Фридрих Шиллер и Россия. - СПб: Пушкинский дом, 2013.

${ }^{29}$ Только в последнее десятилетие на данную тему было опубликовано несколько статей: Лысенкова Е.И. К проблеме шиллеровской традиции в романе Достоевского «Братья Карамазовы» // Историко-литературный сборник. - СПб.: РГПУ им. А.И.Герцена, 2003. - С.108-110; McReynolds S. Dostoevsky and Schiller: National Renewal Through Aesthetic Education //Philosophy and Literature. - 2004. - Vol. 28 (2). - P. 353-366; Герик X.Ю. Достоевский и Шиллер: предварительный опыт поэтологического сравнения // Достоевский: материалы и исследования. Т. 19. С. 5-15; Meyer Н. Was "Schillers" wert sind und was "ein Schiller (wert) ist": Ein- und Wiederkehr als Nicht-Wiederholung in Dostoevskys russischer Philologie als monumentale Intertextualität // R.Helmstetter (Ed.) Schiller: Gedenken - Vergessen - Lesen. - München, Paderborn: Fink, 2010. - S.175-200. Schulz Ch. „Ich habe Schiller auswendig gelernt“. Das ,geistige Ferment“ Schiller im Erzählwerk Dostoevskijs // Goes G. (Ed.) Dostojewskij und Europa. - München, Berlin: Otto Sagner, 2010. - S. 10-41; Криницын А.Б. Достоевский и Шиллер. 2012. Часть 1. URL: http://www.portal-slovo.ru/philology/45241.php; Часть 2. URL: http://www.portal-slovo.ru/philology/45276.php; Часть 3. URL: http://www.portal-slovo.ru/philology/45367.php; Часть 4. URL: http://www.portal-slovo.ru/philology/46077.php (дата обращения: 02.02.2014); Gerigk H.-J. Dostojewskijs Beziehungen zu Friedrich Schiller und E.T.A.Hoffmann. Kontakt-Studie und typologischer Vergleich // Musenalmanach: В честь 80-летия Р.Ю.Данилевского. - СПб.: Нестор-История, 2013.- С.358-363.
} 
Дмитрий Карамазов «исповедуется» в этой главе перед своим младшим братом Алешей посредством цитат из стихотворений Шиллера и Гете. (В настоящей статье мы ограничиваемся анализом лишь шиллеровских цитат.)

«Леша, - сказал Митя, - ты один не засмеешься! Я хотел бы начать ... мою исповедь ... гимном к радости Шиллера. An die Freude! Но я по-немецки не знаю, знаю только, что an die Freude. Не думай тоже, что я спьяну болтаю. Я совсем не спьяну. Коньяк есть коньяк, но мне нужно две бутылки, чтобы опьянеть...» ${ }^{30}$

И далее:

«... Постой, как это ...

Он поднял голову, задумался и вдруг восторженно начал ...» (121)

Начинает Митя, однако, не с оды «К радости» («An die Freude», 1785), а с другого, более позднего стихотворения Шиллера - «Элевзинский праздник» («Das eleusische Fest», 1798), три строфы из которого он цитирует в переводе В.А.Жуковского. Несколько позже наступает черед и оды, из которой цитируются пятая и седьмая строфы в инверсированном порядке, в переводе Ф.И.Тютчева.

Как явствует из данной сцены, восприятие шиллеровской поэзии героем Достоевского своеобразно и отмечено целым рядом очевидных противоречий. С одной стороны, очевидна высокая эмфатическая наполненность и символическая значимость шиллеровских стихов для Мити, который, по его собственным словам, вспоминает данные строки, как правило, в особо маркированных, в частности, в экстремальных жизненных ситуациях. С другой стороны, буквальный смысл каждой конкретной строфы и строчки остается для него зачастую неясным, недопонятым или понятым превратно.

Например, иносказательный сюжет стихотворения «Элевзинский праздник», аллегорически повествующего о переходе номадического, дикого человечества к культуре - вначале как к агрикультуре, прививаемой людям Церерой, - этот чисто просветительский сюжет перетолковывается им в духе евангельской любви к униженному и страждущему человечеству, причем Митя одновременно ощущает себя и субъектом и объектом подобной любви. Поэтому на строфе:

$$
\begin{aligned}
& \text { И куда печальным оком } \\
& \text { Там Церера ни глядит - } \\
& \text { В унижении глубоком } \\
& \text { Человека всюду зрит! (121) }
\end{aligned}
$$

30 Достоевский Ф.М. Братья Карамазовы // Достоевский Ф.М. Собр. соч. в 15 тт. Т. 9. - Л.: Наука, 1991. - С. 120. В дальнейшем текст романа цитируется по этому изданию, с указанием в скобках страниц. 
- герой начинает рыдать:

«Рыдания вырвались вдруг из груди Мити. Он схватил Алешу за руку.

- Друг, друг, в унижении, в унижении и теперь. Страшно много человеку на земле терпеть, страшно много ему бед! /.../Я, брат, почти только об этом и думаю, об этом униженном человеке /.../ Потому мыслю об этом человеке, что я сам такой человек». (121)

Также и следующие строки «Элевзинского праздника» - аллегория, воспевающая приход земледелия:

\author{
Чтоб из низости душою \\ Мог подняться человек \\ С древней матерью-землею \\ Он вступи в союз навек. (121)
}

- воспринимаются импульсивным протагонистом буквально, как «руководство к действию», что порождает с его стороны реакцию по сути комическую:

«Но только вот в чем дело: как я вступлю в союз с землею навек? Я не целую землю, не взрезаю ей грудь; что ж мне мужиком сделаться аль пастушком?» (122) ${ }^{31}$

Еще один пример «продуктивного непонимания» (в духе теории misreading Харальда Блума) текста Шиллера героем Достоевского - интерпретация Митей строки «Оды к радости», которая звучит в тютчевском переводе как «Насекомым сладострастье» (в оригинале: «Wollust war dem Wurm gegeben»). Шиллер обращается к данному образу наделенного «сладострастием» насекомого скорее в качестве простой эмблематической иллюстрации предыдущего высказывания, апеллирующего, в свою очередь, к августиновскому топосу вертикальной «щепи бытия» (а именно: «У груди благой природы // Все, что дышит, радость пьет»). В высказывании Мити же означенный, по смыслу скорее маргинальный, момент оды «К радости» становится ключевым, так как

31 В.Е.Ветловская, напротив, усматривает в данной реплике серьезную логику: «Заметим, что слова о Матери-земле и ее благотворной, животворящей и воскрешающей силе предшествуют в исповеди Мити словам о Мадонне и безусловно прямо соотнесены с ними: ведь тут и там речь идет о том, что противостоит низости» (Ветловская В.Е. «Идеал мадонны» в «Братьях Карамазовых» // Достоевский: исследования и материалы. Т. 15. - СПб.: Наука, 2000. - С. 306). А.Б.Криницын в статье «Достоевский и Шиллер» (см. сн. 29) устанавливает символическую взаимосвязь между именем героя Дмитрий и древнегреческим именованием Цереры - Деметра, а также усматривает аналогию между апологией земледелия, показательной для данного стихотворения Шиллера, и романным эпиграфом о пшеничном зерне из Евангелия от Иоанна; кроме того, исследователь соотносит образ матери-земли с «почвеннической» идеологией Достоевского. Как бы то ни было, в приведенных случаях речь идет о взаимосвязях и символических аналогиях, присутствующих на авторском уровне и не затрагивающих интересующую нас сферу сознания героя. 
предоставляет возможность для проецирования на него представления о себе самом как о носителе «карамазовской натуры»:

«Я, брат, это самое насекомое и есть, и это обо мне специально и сказано. И все мы, Карамазовы, такие же, и в тебе, ангеле, это насекомое живет и в крови твоей бури родит» (121).

Отмеченная, очевидно искажающая авторский смысл, однако эмоционально необыкновенно насыщенная рецепция и интерпретация шиллеровского образа выступает в конце главы даже импульсом для глубокомысленных рассуждений героя о «силе» и «таинственности» красоты, о борьбе в человеческой душе «идеала Мадонны» и «идеала содомского», о «широте» человеческой натуры («... широк человек, слишком даже широк, я бы сузил.» (123)), т.е. порождает, по сути, целый ряд парадигматических формулировок, репрезентативных для дискурсивного уровня данного романа и для антропологии Достоевского в целом.

Нельзя не заметить, что философская лирика Шиллера с ее неизбывным «идейным энтузиазмом» ${ }^{32}$, с ее исключительной способностью презентировать «помысленные чувства и прочувстованные мысли» («gedachte Gefühle und gefühlte Gedanken» ${ }^{33}$ ), «мысль, охваченную аффектом» ${ }^{34}$, - на стилевом уровне вполне соотносима с монологом героя Достоевского, произносимым в состоянии «восторга», даже «исступления» (119). С очевидностью мы имеем дело с ситуацией, когда богатый, доведенный до своеобразного предела интенциональной насыщенности довербальный план «воображаемого» в лакановском понимании данного термина взывает к адекватной реализации в плане «символического», т.е. ищет соответствующий пафосу своего «восторга» язык и находит его - в стихах Шиллера. Именно в шиллеровской стилистике обретает Митя энтузиазм и порывистость, соразмерные движениям его собственной души, и необходимую ему патетику выражения, пусть само содержание текстов немецкого классика, строго говоря, не дает достаточного повода для подобного «присвоения» ${ }^{35}$.

Еще одно явственное противоречие возможно усмотреть в том обстоятельстве, что поэзия Шиллера ассоциируется у героя Достоевского - и в этом Дмитрий Карамазов

\footnotetext{
32 Martini F. Deutsche Literaturgeschichte. - Stuttgart: Metzler, 1968. - S.287.

${ }^{33}$ Sommerhage C. Schillers Lyrik. Eine Apologie // Weimarer Beiträge. - 1992. - Bd. 38. - S. 27.

${ }^{34}$ Михайлов А.В. Читая и перечитывая Шиллера // Шиллер Ф. Избранные произведения. М.: Прогресс, 1984. - C.12.

35 Данное утверждение идет вразрез с популярным мнением, впервые сформулированным Дмитрием Чижевским в статье 1929 г. (см. сн. 11), в соответствии с которым общность двух авторов устанавливается главным образом на уровне «идейного содержания» и «мировоззренческих элементов», заимствуемых у Шиллера Достоевским. Исключительно на содержательных моментах схождения Достоевского и Шиллера строит свой анализ и А.Б.Криницын. (см. сн. 29).
} 
разделяет установку всего XIX века ${ }^{36}$, - с «высоким» строем чувств, мыслей и поступков, т.е. с «идеалом Мадонны», по его собственному выражению. Обращается же он к этой поэзии, однако, как носитель скорее противоположного идеала - «идеала содомского»:

«И когда мне случалось погружаться в самый, самый глубокий позор разврата (а мне только это и случалось), то я всегда это стихотворение о Церере и о человеке читал» (122).

Если попытаться сделать промежуточный вывод, придем к предположению, что сама рецитация шиллеровских стихов - именно чтение вслух, декламация - обладает для декламирующего героя априори высоким самоидентификационным потенциалом. Набор изъятых из синтаксических взаимосвязей экскламационных, семантически (произ)вольно наполняемых «ключевых» слов-символов, таких, как «человек», «человечество», «униженье», «гражданин», «други, братья, на колена» (в пер. Тютчева) и т.д. - а также сама ритмика, мелодика, звучность стихов оказываются при этом важнее, нежели смысл произносимого текста в строгом смысле слова. «Исправляло ли оно меня? Никогда!», говорит Митя о стихотворении «Элевзинский праздник» (122).

Соответственно, несомое рецитируемым текстом количество сообщаемой энергии, «восторг», импульс (impuls), если вспомнить о происхождении этого слова от латинского глагола impello - «приводить в движение», «гнать», «подгонять», «подталкивать», «ударять», «бить», «толкать», - наделяется более важным значением, нежели «смысловое», в данном случае исправляюще-этическое воздействие. В означенном плане важна, наряду с перформативной значимостью, также и высокая коммуникационная валентность подобной «импульсирующей» декламации, телесно затягивающей в поле своей инфицирующей вибрации также и присутствующих. Ср. Митя говорит брату, слушающему его облеченную в шиллеровские строфы «исповедь»: «Вот и у тебя глазенки горят» (122).

Подобная рецепция поэзии Шиллера, заметим, вполне соотносима с литературоведческой оценкой стиля и габитуса шиллеровской «философской лирики» (Gedankenlyrik), для которой Герхард Шторц еще в 1968 г. отмечал «ярко выраженную потребность ... в звуковом воздействии, в мощной ритмике и в музыкальности...» ${ }^{37}$, а Герберт Цюзарц писал, в свою очередь, что Шиллер «скорее выпадет из слова, нежели из тона» ${ }^{38}$. Данная - нацеленная на чувственное восприятие, акустическая - сторона лирики

\footnotetext{
${ }^{36}$ См. : Михайлов А.В. Читая и перечитывая Шиллера . - С. 6; Friedl G. Verhüllte Wahrheit und entfesselte Phantasie. Die Mythologie in der vorklassischen und klassischen Lyrik Schillers. Würzburg: Koenigshausen\&Neumann, 1987.

${ }^{37}$ Storz G. Gesichtspunkte für die Betrachtung von Schillers Lyrik //Jahrbuch der Schillergesellschaft. - 1968. - Bd. 12. - S. 262.

${ }^{38}$ Cysarz H. Die dichterische Phantasie Friedrich Schillers. - Tübingen: Niemeyer, 1959. - S. 56.
} 
Шиллера, придающая его текстам на прагматическом уровне, по выражению Й.Бернауэра, качество «апеллятивного песнопения» ${ }^{39}$, по-видимому, оказывается способной не только вводить содержание и «формовать», парцеллировать его на ритмические периоды, но и, в отдельных случаях, даже его, это содержание, заменять. При этом «идейная», собственно содержательная сторона неизбежно оттесняется на второй план.

Уместно процитировать в данном плане суждение Х. Шлаффер:

«Средства, к которым прибегает Шиллер - по преимуществу формальные и риторические, так что воздействие его поэзии основано на /.../ акустических, внешних эффектах. Ассоциации, которые могли бы вызвать отдельные образы, не развиваются, но теснят друг друга, не взаимопроникая в синэстетической взаимодополнительности. Вместо синэстезии наступает анестезия. Из темного хаоса образов выступают лишь обломки, отдельные слова, которые молниеносно проникают в воображение читателя» ${ }^{40}$.

Основываясь на рассуждениях исследовательницы, возможно сделать предположение о двух возможных способах чтения лирики Шиллера - про себя, тогда будет восприниматься в первую очередь текст, и стихотворение останется в пределах собственной литературности. И - вслух, в этом случае доминировать будет чувственная, звуковая, акустическая сторона: так читает индивидуум, ищущий, подобно Мите Карамазову, выхода своим «восторгу» и импульсции. В данном, последнем случае над смыслом начинает доминировать патетика и ритмика, а над письменным текстом голосовые и телесные, артикуляционные, мимические, пластические практики презентации. И герой Достоевского в полной мере отдает дань этим практикам. Неоднократно упоминается о его «восторженном состоянии» $(118 ; 121)$ в момент беседы с Алешей, о его «каком-то почти исступлении» (119), исповедь его прерывается рыданиями (122). «Исступающая» за границы собственной телесности экспансивность, почти переходящая в агрессию, проявляется, в частности, в его заявлении: «Я бы взял тебя, Алешка, и прижал к груди, да так, чтобы раздавить ...» (118-119).

Шиллер сам, по сути, предвосхитил подобную рецептивную практику, когда в переписке с философом И. Г. Фихте упомянул о произведениях, «на которые всегда будет спрос», потому что они «производят эффект, не зависящий от их логического

\footnotetext{
${ }^{39}$ Bernauer J. „Schöne Welt, wo bist du?“ Über das Verhältnis von Lyrik und Poetik bei Schiller. - Berlin: Schmidt, 1995. - S. 236.

${ }^{40}$ Schlaffer H. Die Ausweisung des Lyrischen aus der Lyrik. Schillers Gedichte // G. Buhr, F.A. Kittler \& H.Turk (Ed) Das Subjekt in der Dichtung. Festschrift für Gerhard Kaiser . - Würzburg: Koenigshausen\&Neumann, 1990. S. 529. Курсив мой - Л.П.
} 
содержания», в силу того, что «в них индивидуум вживе себя отпечатывает» («sich ein Individuum lebend abdrückt» ${ }^{41}$ ).

Метафора «живого отпечатка» некой энергии, оставляющей «след» и не зависящей от «логического содержания» (ср. также приведенную в начале оценку Достоевским шиллеровского воздействия на русскую культуру: « ... в душу русскую всосался, клеймо в ней оставил...»), - энергии, которую автор непосредственно инвестирует в текст, в его тон и ритм, наводит на мысли о специфической механике протекания рецептивных процессов, которые в данном случае вряд ли возможно будет объяснить при помощи теории интертекстуальности. С очевидностью, при восприятии декламируемого стихотворения с ярко выраженной апеллятивной структурой, подобного оде «К радости», в меньшей степени оказывается возможным говорить о деконтекстуализации и реконтекстуализации его в сознании слушателя или о декодировании и новом кодировании сигнификантов. Скорее речь должна идти об акустическом - телесном, физическом - транслировании импульсов и последующем их инкорпорировании на рецептивном - слушательском уровне. Возникает, таким образом, основанная на оральности и телесности коммуникационная цепочка или сеть, в рамках которой реципируемый материал передается не от слова к слову и не от текста к тексту, но от субъекта к субъекту или, точнее, от одного (декламирующего) тела к другому, воспринимающему эту декламацию и от нее воспламеняющемуся или, если говорить словами Шиллера-Достоевского, позволяющему «вживе на себе отпечатать» некий личностный импульс в виде «клейма». Именно таким, т.е. вполне соответствующим авторским намерениям был, как теперь очевидно, механизм воздействия шиллеровской поэзии на юного Достоевского (который, как помним, «вызубрил Шиллера, говорил им, бредил им...» ${ }^{42}$.

Похожим образом реагирует публика и на знаменитую Пушкинскую речь самого Достоевского, произнесенную в здании московского Дворянского собрания 8 июня 1880 г. Как представляется, центральным событием данного исторического заседания стала не столько буквально воспринятая суть речи, сколько непосредственная реакция слушателей на ее пафос, интонацию и на отдельные ключевые слова. И в самом деле, ситуация восприятия данной речи публикой, многократно описанная очевидцами ${ }^{43}$, строилась в

\footnotetext{
${ }^{41}$ От 3 августа 1795 г. Цит. по: Schubert W. Antike Mythologie und sittliche Weltordnung. Anmerkungen zum poetischen Werk Friedrich Schillers // „Dass eine Nation die andere verstehen möge. Festschrift für Marian Szyrochi zu seinem 60.Geburtstag. - Amsterdam: Rodopi, 1988. - S. 677.

42 Достоевский Ф.М. Полное собрание сочинений и писем. В 30 т. Т. 28 (1). - С.69.

43 В частности, акцентирование качеств Достоевского-оратора и моментов непосредственного воздействия его речи на публику показательно для воспоминаний юриста и культурного деятеля А.Ф.Кони (Кони А.Ф. На жизненном пути. Т. 2. - М.: Товарищество И.Сытина, 1916. - С.99). См. также: Амфитеатров А.В. Достоевский на Пушкинских празднествах 1880 года // Сегодня - 1921 - N 267 - 270. - 23 - 26 ноября.
} 
серьезной мере на «шиллеровском» по своему истоку ферменте ${ }^{44}$ : на задействовании рассмотренного выше телесно-орального механизма «живого отпечатывания» себя говорящим индивидуумом в сознании слушателя. Недаром исследователи до сих пор гадают, что в большей мере сделало данное выступление национальным мифом и культовым текстом - содержание или небывало эмфатическая реакция на него публики. ${ }^{45}$.

${ }^{44} \mathrm{O}$ «шиллеровском» подтексте Пушкинской речи Достоевского писал Т.Манн в своем эссе о Шиллере 1955 г., правда, имея в виду скорее содержательные аналогии. См: Mann Th. Versuch über Schiller. - Frankfurt a .M.: S. Fischer, 1955. - S. 72.

${ }^{45}$ См.: Волгин И.Л. Последний год Достоевского: исторические записки. М.: Советский писатель, 1986. - С. 215; Потапова Г.Е. От «протеизма» к «всемирной отзывчивости». (Очерк истории одной идеи) // Достоевский: Материалы и исследования. Т.16. - СПб.: Наука, 2001. - С. 51-61. 